\title{
Rupture Process of the Kobe, Japan, Earthquake of Jan. 17, 1995, Determined from Teleseismic Body Waves
}

\author{
Masayuki Kikuchi*.1 and Hiroo Kanamori ${ }^{2}$ \\ ${ }^{1}$ Department of Physics, Yokohamat City University, \\ Kanazawa-ku, Yokohama 236, Japan \\ ${ }^{2}$ Seismological Laboratory, California Institute of Technology, \\ Pasadena, CA 91125, U.S.A.
}

\begin{abstract}
The source process of the 1995 Kobe earthquake is determined using teleseismic body waves. The source parameters obtained for the total source are: focal mechanism [strike, dip, rake] equal to [233", 86", 167"], nearly pure strike-slip with an EW compression axis; the seismic moment, $M_{\mathrm{o}}=2.5 \times 10^{19} \mathrm{Nm}\left(M_{\mathrm{w}}=6.9\right)$; and source duration $T=11 \mathrm{~s}$. The rupture process consists mainly of three subevents with source durations of $5-6 \mathrm{~s}$ : two are nearly pure strike-slip with slightly different fault strikes, and the other is dip-slip. Combining the source location with the aftershock distribution, we infer that the first subevent is a bilateral rupture and the later subevents are unilateral propagating NE and reaching the Kobe area. The total fault length is $40 \mathrm{~km}$, the averaged dislocation is $2.1 \mathrm{~m}$, and the averaged stress drop is $8 \mathrm{MPa}$. These source parameters indicate that the Kobe earthquake was a typical shallow inland earthquake which occurred on a previously mapped Quaternary fault zone. The directivity toward Kobe determined from teleseismic data was probably one of the main factors responsible for the heavy damage. The combined use of regional networks and teleseismic networks as demonstrated in this study will continue to be important for rapidly assessing the overall social impact of an earthquake in the very early stage of sequence.
\end{abstract}

\section{Introduction}

At dawn on January 17, 1995 (5:46:52 a.m. Japan local time), a violent earthquake struck the port city of Kobe and its surrounding areas in western Japan (Fig. 1). This earthquake was named the "Hyogoken Nanbu (Southern Hyogo Prefecture) earthquake" by the Japan Meteorological Agency (JMA), but here it is referred to as the Kobe earthquake. The hypocentral parameters given by JMA were: origin time $=95 / 01 / 17 \quad 05: 46: 52$ JST $\quad(95 / 01 / 16$ 20:46:52 GMT $)$; epicenter $=\left(34.61^{\circ} \mathrm{N}, 135.04^{\prime \prime} \mathrm{E}\right)$; depth $=14.3 \mathrm{~km}$; magnitude $\left(M_{\mathrm{J}}\right)=7.2$.

This was one of the most damaging earthquakes in the recent history of Japan. According to the official announcement, the casualty toll reached 5,502 dead, 2 missing, and more than 41,000 injured. It was recognized later that more than 500 people who had been receiving treatment at hospitals died shortly after, so the overall death toll exceeded
6,000. More than 80,000 houses and buildings were destroyed, and nearly 100,000 were damaged. The total financial loss including the damage to roads, harbor facilities, electricity, gas, water, and telephone utilities, rivers, and schools was estimated to be 9,600 billion yen (nearly $\$ 100$ billion).

In this paper we investigate seismic data to determine the source characteristics of this earthquake with the hope of gaining insight into the cause of the very heavy damage inflicted in the city of Kobe.

\section{Waveforms at a Regional Network of Broadband Seismographs}

The regional broadband network of the Yokohama City University (YCU) and the National Research Institute for Earth Science and Disaster Prevention (NIED) in the southern Kanto district recorded large amplitude waves generated from this earthquake. Figure 2 shows the waveforms recorded

Received July 27, 1995; Accepted November 24, 1995

* To whom correspondence should be addressed. Present address: Earthquake Research Institute. The University of Tokyo, Yayoi, Bunkyo-ku, Tokyo 113, Japan 


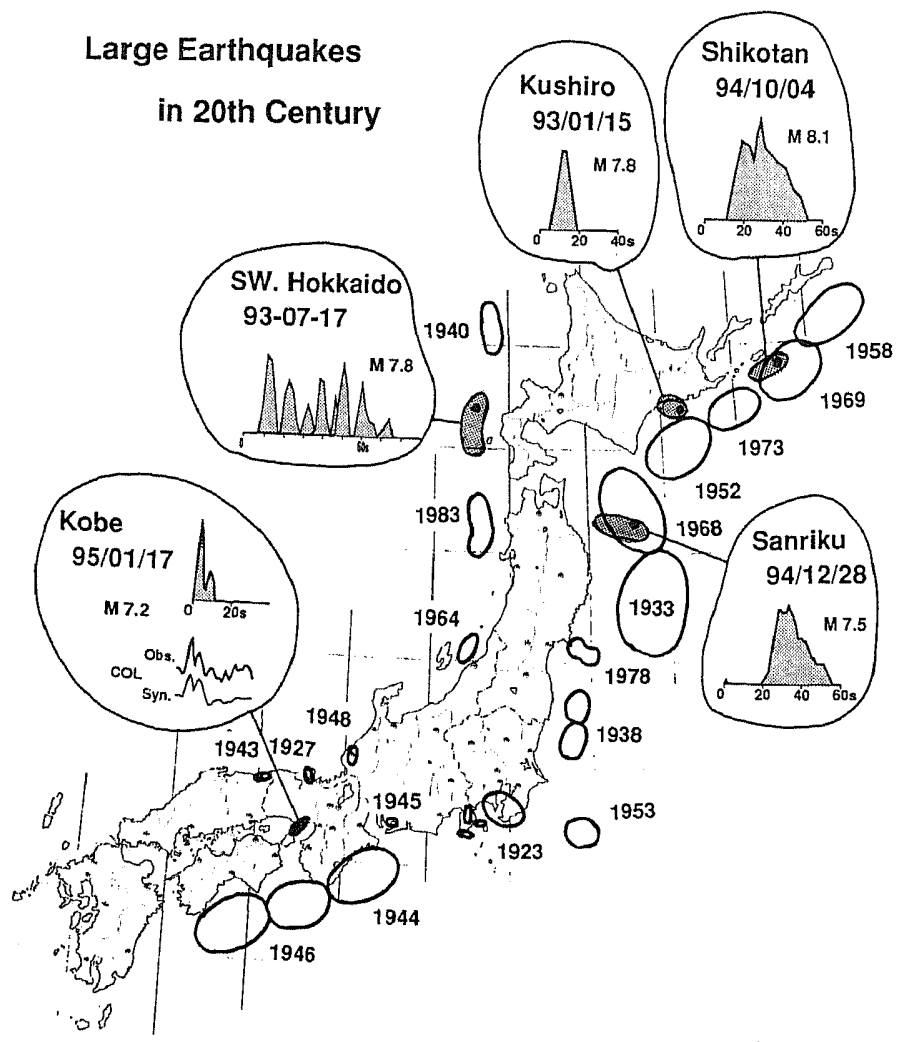

Fig. 1. The location of the 1995 Kobe earthquake and the large earthquakes in and around Japan since the 1923 great Kanto earthquake. Moment-rate functions are shown for the recent five earthquakes.

at three stations of this network and MAJO of the IRIS network. The waveforms are converted into ground motion displacements. As seen from this figure, MAJO is close to the P-wave nodal plane. The narrow-band records are also shown in Fig. 2 , where the components with frequencies of less than $0.2 \mathrm{~Hz}$ are filtered off. The JMA magnitude is currently determined by means of displacement seismographs with a natural period of $5-6 \mathrm{~s}$, using the relation:

$$
M_{\mathrm{J}}=\log A+1.73 \log \Delta-0.83
$$

where $A$ is the peak amplitude measured in $\mu \mathrm{m}$ and $\Delta$ is the epicentral distance in $\mathrm{km}$. Substituting the values of $A$ and $\Delta$ given in Fig. 2 into the above, we obtain $M_{\mathrm{J}}=6.9 \pm 0.1$. However, since the epicenter was nearly $400 \mathrm{~km}$ from the southern Kanto network, these regional networks alone could not determine more detailed source parameters, and data from teleseismic stations were required.

\section{Teleseismic Body Wave Inversion}

We collected the broadband seismograms recorded by the IRIS network and chose the stations at distances between $30^{\circ}$ and $100^{\circ}$ as shown in Fig. 3 . The azimuthal coverage is fairly good. The records were converted into ground motion displacement and bandpassed between $2 \mathrm{mHz}$ and $1 \mathrm{~Hz}$. We used 38 body wave records (vertical P- and SHcomponents) observed at 22 stations. The station parameters are given in Table 1. We inverted these records into a sequence of point dislocation sources by means of the iterative deconvolution method of Kikuchi and Kanamori (1991).

$\mathrm{P}$-wave records as well as the SH-wave polarity at several stations are displayed in Fig. 3. Most of the $\mathrm{P}$-waves consisted of a few pulses with durations of about $5 \mathrm{~s}$ and the relative height of the pulse sequence varied from station to station. This suggests that the earthquake source consisted of a 


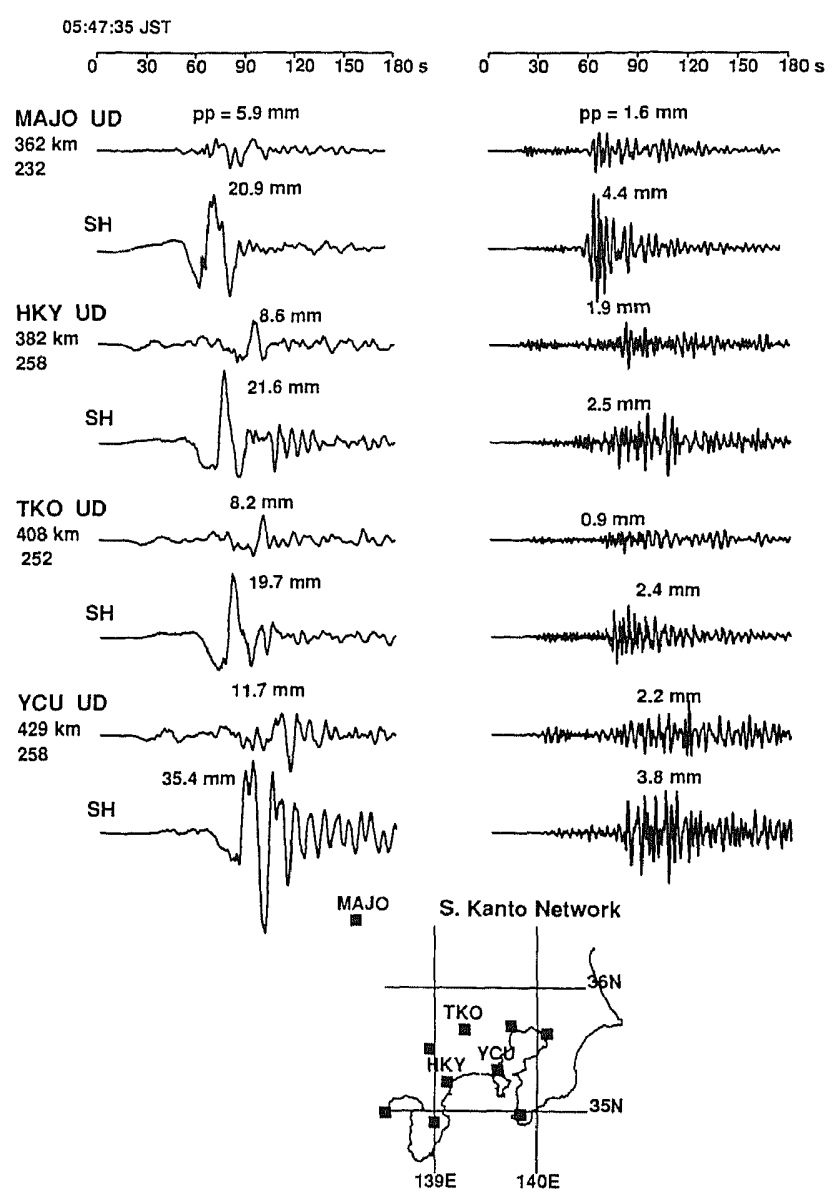

Fig. 2 Broadband seismograms recorded by the regional network in southern Kanto district and at MAJO (IRIS). They are converted into ground motion displacements. The right column shows the low-cut filtered ground displacement with a cut-off frequency of $0.2 \mathrm{~Hz}$.

few discrete subevents with different mechanisms.

Therefore, in the inversion of teleseismic body waves, we allowed the mechanism to change during rupture. In synthesizing waveforms, we used the standard Jeffreys-Bullen model both for the source region and for receiver sites. We first assumed a trapezoidal source time function and sought point dislocations at grid points along a horizontal line. We found that three sources were sufficient to produce a good waveform match between the observed and synthetic waveforms. We varied the source depth from 5 to $15 \mathrm{~km}$ with an increment of $1 \mathrm{~km}$ and obtained the best match for a depth of $8 \mathrm{~km}$. Next, fixing the location and mechanism of the three point sources, we re-determined the individual source time functions by the least-squares method.

The final solution obtained is given in Table 2. Three subevents are located on a line striking NESW; the first one at the epicenter, and the second and third subevents about 10 and $15 \mathrm{~km}$ northeast of the epicenter, respectively. The first and third subevents are nearly pure strike-slip with slightly different fault strikes while the second subevent is dip-slip with an EW compression axis. If the above locations of the subevents are taken literally, the result suggests a unilateral rupture propagation toward the NE, but the first subevent itself could have been bilateral.

In fact, the spatial distribution of the aftershocks 


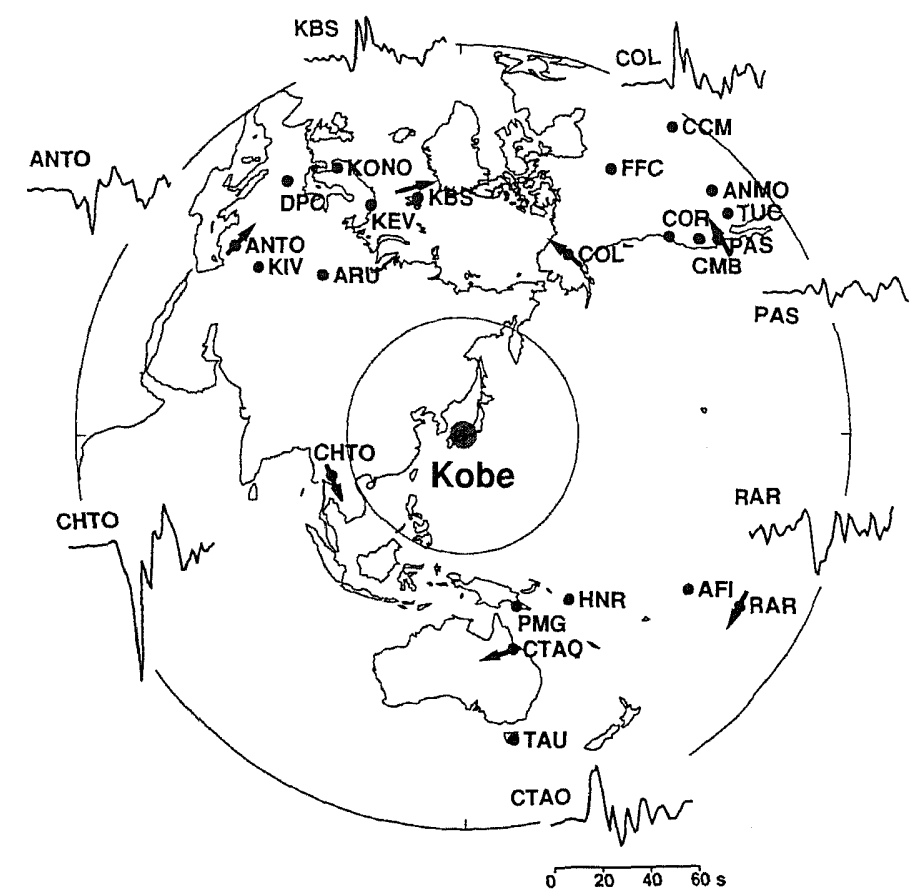

Fig. 3. IRIS broadband seismograph stations within teleseismic distance $\left(30-100^{\circ}\right)$. Waveforms show the initial portion of P-waves. The arrow indicates the initial polarity of the $\mathrm{SH}$-waves.

Table 1. List of station parameters.

\begin{tabular}{lcccl}
\hline Station & $\begin{array}{c}\text { Azimuth } \\
\text { degree }\end{array}$ & $\begin{array}{c}\text { Back azimuth } \\
\text { degree }\end{array}$ & $\begin{array}{c}\text { Distance } \\
\text { degree }\end{array}$ & Phase \\
\hline FFC & 29.6 & 315.2 & 78.2 & P, SH \\
COL & 30.9 & 275.4 & 53.7 & P, SH \\
CCM & 34.9 & 323.3 & 95.6 & P, SH \\
ANMO & 46.1 & 313.7 & 89.8 & P, SH \\
COR & 46.6 & 302.9 & 73.8 & P, SH \\
TUC & 50.4 & 311.3 & 89.0 & P \\
CMB & 50.9 & 305.8 & 79.3 & P, SH \\
PAS & 53.0 & 307.5 & 83.0 & P, SH \\
RAR & 121.6 & 311.2 & 83.3 & P,SH \\
AFI & 124.2 & 315.5 & 70.0 & P \\
HNR & 147.1 & 333.3 & 50.0 & P,SH \\
PMG & 163.1 & 345.9 & 45.5 & P \\
CTAO & 167.2 & 348.8 & 55.7 & P,SH \\
TAU & 170.8 & 349.7 & 78.3 & P,SH \\
CHTO & 253.1 & 56.3 & 35.6 & P,SH \\
KIV & 309.3 & 62.1 & 68.5 & P \\
ANTO & 309.6 & 55.8 & 76.7 & P, SH \\
ARU & 318.7 & 79.2 & 54.6 & P \\
DPC & 325.3 & 47.3 & 79.3 & P,SH \\
KONO & 334.8 & 43.8 & 75.6 & P,SH \\
KEV & 338.4 & 60.9 & 63.6 & P, SH \\
KBS & 349.5 & 51.5 & 61.9 & P,SH \\
\hline
\end{tabular}

relative to the main shock suggests a southwestward rupture extension from the epicenter (Hirata, 1995; Yoshida, 1995). Therefore, the first subevent was probably a bilateral rupture and the later subevents were unilateral propagating NE. Source durations obtained for the 1st, 2 nd, and 3 rd subevents are 5-6, $4-5$, and $5-6 \mathrm{~s}$, respectively. For rough estimation of the fault length, we assume that two-thirds of the source duration is allotted for rupture propagation, and put 4,3 , and $4 \mathrm{~s}$ as the rupture times of the successive three subevents. Then, assuming that the rupture velocity $(v)$ is $3 \mathrm{~km} / \mathrm{s}$, rigidity $(\mu)$ is $30 \mathrm{GPa}$, and aspect ratio (length/width) is 2 , we estimated the fault area, dislocation, and stress drop for the individual subevents. The results are given in Table 2. The tensorial sum of the three double-couples yields a moment tensor with a slight non-doublecouple component. The best matching doublecouple mechanism is [strike, dip, rake] equal to $\left[233^{\circ}, 86^{\circ}, 167^{\circ}\right]$, nearly a pure right-lateral strikeslip, with seismic moment of $M_{\mathrm{o}}=2.5 \times 10^{19} \mathrm{~N} \mathrm{~m}$ $\left(M_{\mathrm{w}}=6.9\right)$ and a non-double-couple component of $3.7 \%$. The source duration (rupture time plus dislocation rise time) is $T=11 \mathrm{~s}$, and the total length of the fault is estimated as: 
Table 2. Source parameters for the final solution.

\begin{tabular}{cccccccc}
\hline No. & $\begin{array}{c}\text { Time } \\
(\mathrm{s})\end{array}$ & $\begin{array}{c}\text { Distance } \\
(\mathrm{km})\end{array}$ & $\begin{array}{c}M_{\mathrm{o}} \\
\left(\times 10^{10} \mathrm{~N} \mathrm{~m}\right)\end{array}$ & $\begin{array}{c}\text { [Strike, dip, rake] } \\
(\text { degree })\end{array}$ & $\begin{array}{c}\text { Area } \\
\left(\mathrm{km}^{2}\right)\end{array}$ & $\begin{array}{c}\text { Slip } \\
(\mathrm{m})\end{array}$ & $\begin{array}{c}\Delta \sigma \\
(\mathrm{MPa})\end{array}$ \\
\hline 1 & $0-6$ & 0 & 1.89 & {$[231,86,172]$} & $24 \times 12$ & 2.2 & 10 \\
2 & $3-8$ & $5-10$ & 0.21 & {$[212,54,82]$} & $9 \times 4.5$ & 1.7 & 20 \\
3 & $6-11$ & $15-20$ & 0.56 & {$[236,88,155]$} & $12 \times 6$ & 2.6 & 23 \\
\hline Total & $0-11$ & & 2.49 & {$[233,86,167]$} & $40 \times 10$ & 2.1 & 8 \\
\hline
\end{tabular}

$$
L=24+9+12-5=40 \mathrm{~km} \text {, }
$$

where we assume an overlap of $5 \mathrm{~km}$ between the second fault segment and the others. This value is consistent with the length of the aftershock area. For the total source, we obtained an averaged dislocation $(\bar{D})$ of $2.1 \mathrm{~m}$, and a stress drop $(\Delta \bar{\sigma})$ of $8 \mathrm{MPa}$. The value of $\bar{D}$ is in good agreement with the fault slip, 1-2 m, observed along the Nojima Fault on Awaji Island (Nakata et al., 1995).

It should be mentioned, however, that the rupture velocity of $v=3 \mathrm{~km} / \mathrm{s}$ is somewhat larger than the value usually used for shallow earthquakes: $2.0-2.5 \mathrm{~km} / \mathrm{s}$. If we use $v=2.5 \mathrm{~km} / \mathrm{s}$, then the fault length becomes $L=20+7.5+10-5 \approx 33 \mathrm{~km}$. Although this estimate is significantly smaller than the length of the aftershock zone, it cannot be ruled out since the aftershock area does not necessarily coincide with the co-seismic rupture area. If $v=$ $2.5 \mathrm{~km} / \mathrm{s}$, the fault area should be multiplied by a factor of 0.8 , the slip by 1.3 , and the stress drop by 1.4. In what follows, we adopt the former source parameters as given in Table 2 .

The spatio-temporal distribution of faulting is shown in Fig. 4. The resultant synthetic waveforms are compared with those actually observed in Fig. 5. The major features of the observed waveforms were satisfactorily reproduced with the synthetic waveforms of all stations. The normalized variance is $32 \%$. Figure 4 (a) shows the source time functions for the three subevents as well as for the total source. More than two-thirds of the total seismic moment was released by the first subevent. In drawing the fault trace in Fig. 4(b), the epicenter determined by JMA is adopted and the estimated fault length together with the fault strike are taken into account. The spatial resolution in the present inversion is about $5 \mathrm{~km}$, which corresponds to a time resolution of $1 \mathrm{~s}$. The shaded zone in Fig. 4(b) indicates the uncertainty of fault trace location. The cross section of the fault plane in Fig. 4(c) is (a)

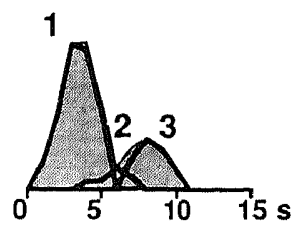

(b)
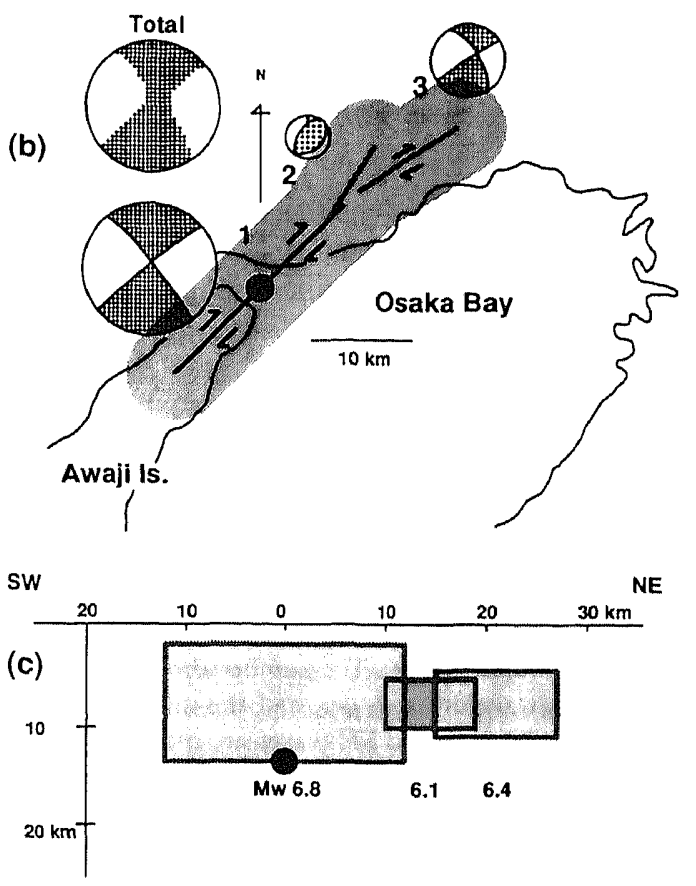

Fig. 4. Final solution of the present body wave inversion. Three subevents with different mechanisms are obtained. (a) Moment-rate functions for the individual subevents (thick curve) and for the total source (thin curve). (b) Spatial distribution of the fault trace. The shaded zone indicates the uncertainty of the location $( \pm 5 \mathrm{~km})$. (c) Vertical SW NE striking cross section showing the inferred fault segments. 


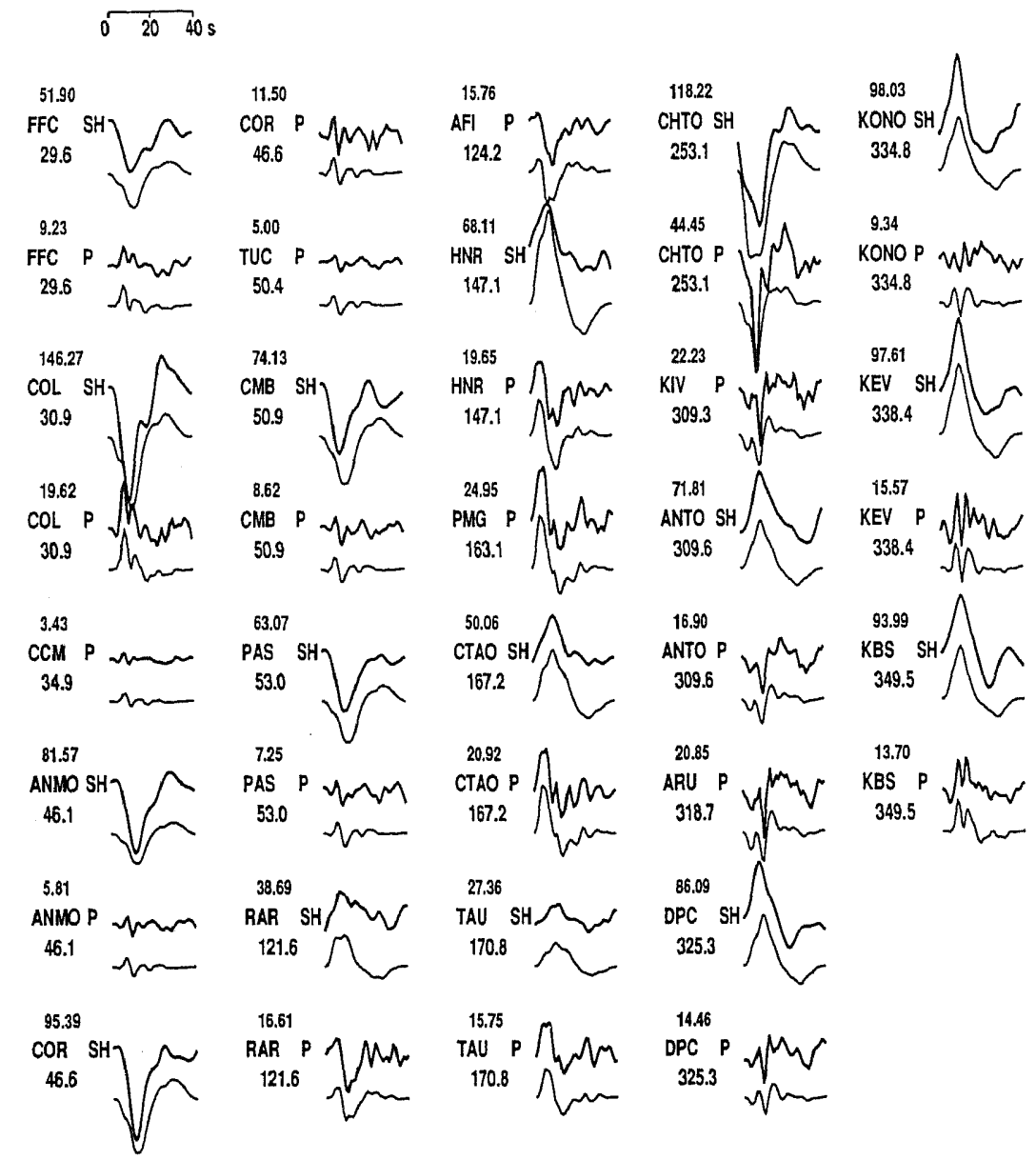

Fig. 5. Comparison of synthetic waveforms (lower trace) for the final solution and observed waveforms (upper trace). The number above the station code indicates the peak-to-peak amplitude of the observed waveforms in $\mu \mathrm{m}$, and the number below the station code indicates the station azimuth in degrees. $\mathrm{P}$-waves and $\mathrm{SH}$-waves are plotted with a respective common vertical scale.

drawn so that the average depth is $8 \mathrm{~km}$.

In order to check the significance of the second and third subevents, the contributions from these fault segments to the synthetic waveforms were investigated. Figure 6 compares the synthetic waveforms computed for one, two and three fault segments with the observed waveforms. The normalized variances are 59,45 , and $32 \%$ for cases $1,1+2$, and $1+2+3$ subevents, respectively. It is clear that the first subevent alone cannot explain the later portion of the observed records. The third subevent is certainly needed to improve the waveform match, while the significance of the second subevent, with a dip-slip mechanism, is marginal in the sense that a similar contribution could be resolved into dipslip components of the 1st and 3rd subevents.

\section{Discussion}

The extent of co-seismic rupture of this earthquake is a matter of considerable debate. A surface rupture was observed over nearly $10 \mathrm{~km}$ of the Nojima Fault on Awaji Island, while no distinct surface fault was found near the Kobe area on the mainland (Nakata et al., 1995). On the other hand, the aftershock area covers a linear zone extending beyond Kobe City. Another remarkable observa- 


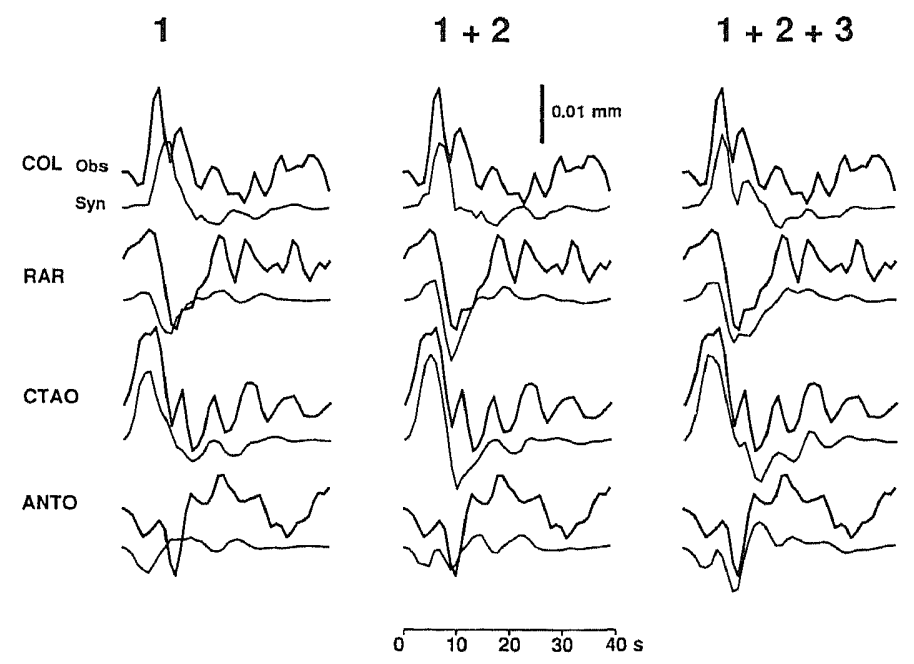

Fig. 6. Waveform comparisons for three cases: left, contribution from only the first subevent; middle, contribution from the first and second subevents; right, contribution from all the three subevents.

tion is that the most heavily damaged zone in Kobe City is slightly shifted to the south from the aftershock zone (Shimamoto, 1995).

The questions are: (1) Did the buried fault break as far NE as the Kobe area? (2) If it did, is it the main fault connected to the previously mapped surface Quaternary faults? (3) Can we pinpoint the fault trace and relate it to the aftershock zone and the heavily damaged zone? For question (1), our analysis shows that the fault did reach the Kobe area. Regarding question (2), there is no evidence that any of the known Quaternary surface faults moved during the earthquake, but the aftershock area coincides with the zone of these Quaternary faults. Threfore, it is reasonable to think that the buried fault is the principal fault and the mapped Quaternary faults are the secondary faults splaying out to the surface; during the Kobe earthquake, slip occurred only on the buried portion of the fault. Question (3) is critically important for understanding the spatial distribution of the damaged area. The spatial resolution of our teleseismic analysis is too limited to determine the details, but we believe the directivity toward Kobe determined from our analysis is one of the main factors responsible for the heavy damage.

Since the first subevent probably ruptured southwest too, there must be significant directivity toward Awaji Island. However, the relatively light damage on Awaji Island as compared with that in the Kobe area is probably due to differences in other factors such as the total population and types of structures.

The source parameters such as moment magnitude $\left(M_{\mathrm{w}}=6.9\right)$, rupture extent $(L \approx 40 \mathrm{~km})$, and stress drop $(\Delta \sigma=8 \mathrm{MPa})$ indicate that the Kobe earthquake was a typical shallow inland earthquake. In Japan, three major inland earthquakes have occurred since 1927: the 1927 Tango earthquake $\left(M_{\mathrm{J}}=7.3, \Delta \sigma=12 \mathrm{MPa}\right)$; the 1943 Tottori earthquake $\left(M_{\mathrm{J}}=7.2, \Delta \sigma=8 \mathrm{MPa}\right)$; and the 1948 Fukui earthquake $\left(M_{\mathrm{J}}=7.1, \Delta \sigma=10 \mathrm{MPa}\right)$ (Kanamori, 1973). The locations of these earthquakes are shown in Fig. 1. They are very similar in size and mechanism (nearly pure strike-slip).

Our study demonstrates that a rapid analysis of broadband teleseismic data which have become available thanks to recent developments in seismographs, data acquisition systems, and computer networks enables us to determine important source characteristics such as the size, mechanism, and rupture directivity of earthquakes. As we have shown above, directivity has an important bearing on the extent and pattern of damage; therefore, this type of study is capable of playing an important role for rapid emergency operations immediately after a damaging earthquake. In principle, real-time regional networks are probably more important for this purpose, but to take full advantage of regional networks a method to handle the source finiteness adequetely needs to be developed. Such a method 
does not yet exist. Therefore, the combined use of regional networks and teleseismic networks, as we have demonstrated in this study, will continue to be important for assessing the overall social impact of an earthquake in the very early stage of sequence.

This research was partially supported by the Grant-inAid for Scientific Research No.04452067 from the Ministry of Education, Science, Sports and Culture of Japan, and by the National Science Foundation Grant EAR-9303804, U.S.A. Contribution No. 5579, Division of Geological and Planetary Sciences, California Institute of Technology, Pasadena, California 91125.

\section{REFERENCES}

Hirata, N., Aftershocks of the Hyogo-ken Nanbu earthquake, Kagaku, 65, 199, 1995 (in Japanese).

Kanamori, H., Mode of strain release associated with major earthquakes in Japan, Annu. Rev. Earth Planet. Sci., 1, 213-239, 1973.

Kikuchi, M. and H. Kanamori, Inversion of complex body waves-III, Bull. Seismol. Soc. Am., 81, 2335-2350, 1991.

Nakata, T., K. Yomogida, J. Okada, T. Sakamoto, K. Asahi, and N. Chida, Surface fault ruptures associated with the 1995 Hyogoken-Nanbu earthquake, J. Geogr., 104, 127-142, 1995 (in Japanese with English abstract).

Shimamoto, T., Heavily damaged zone in the Kobe earthquake, Kagaku, 65, 195-198, 1995 (in Japanese).

Yoshida, A., 1995 Hyogoken-Nanbu Earthquake, Chishitsu News, 486, 6-11, 1995. 